\title{
LEADERSHIP BEHAVIOURS AND HEALTHCARE RESEARCH PERFORMANCE: PROSPECTIVE CORRELATIONAL STUDY
}

\section{Authors:}

Vanash M Patel MSc MRCS $\mathrm{PhD}^{1}$, Hutan Ashrafian BSc MRCS $\mathrm{PhD}^{1}$, Chudy Uzoho MBBS $\mathrm{BSc}^{1}$, Nikolaos Nikiteas $\mathrm{MD} \mathrm{PhD}^{2}$, Pietro Panzarasa $\mathrm{PhD}^{3}$, Nick Sevdalis BSc MSc $\mathrm{PhD}^{4}$, Ara Darzi FMedSci HonFREng KBE ${ }^{1}$, Thanos Athanasiou PhD FRCS FETCS ${ }^{1}$

\section{Affiliations:}

${ }^{1}$ Department of Surgery and Cancer, Imperial College London. 10th Floor QEQM Building, St Mary's Hospital, London W2 1NY, UK

${ }^{2}$ Second Department of Propedeutic Surgery, University of Athens School of Medicine, Laiko General Hospital, Agiou Thoma 17 Athens, Greece

${ }^{3}$ School of Business and Management, Queen Mary University of London. Francis Bancroft Building, Mile End Road, London, E1 4NS

${ }^{4}$ Centre for Implementation Science, Health Service \& Population Health Department, King's College London, Denmark Hill, London SE5 8AF

*Correspondence to: Mr Vanash M Patel, Clinical Research Fellow, Department of Surgery and Cancer, 10th Floor, QEQM Wing, St Mary’s Hospital, London W2 1NY.

Email: vanash.pate106@imperial.ac.uk

Funding: Sevdalis' research was funded by the UK National Institute for Health Research (NIHR) Collaboration for Leadership in Applied Health Research and Care South London at King's College Hospital NHS Foundation Trust. The views expressed are those of the authors and not necessarily those of the NHS, the NIHR or the Department of Health. 


\section{ABSTRACT}

\section{Objectives}

The aims of the study were to determine whether differences in leadership selfperception/behaviour in healthcare researchers may influence research performance, and to evaluate whether certain leadership characteristics are associated with enhanced leadership efficiency in terms of motivation, effectiveness and satisfaction.

\section{Design and Participants}

All Faculty of Medicine Professors at Imperial College London ( $\mathrm{n}=215)$ were sent the Multifactor Leadership Questionnaire (MLQ) Self form as a means of evaluating self-perception of leadership behaviours.

\section{Main outcome measures}

For each professor, we extracted objective research performance measures (total number of publications; total number of citations; and h index) from January 1st 2007 to December 31 st 2009. The MLQ measured three leadership outcomes, which included motivation, effectiveness and satisfaction. Regression analysis was used to determine associations.

\section{Results}

A total number of 90 responses were received, which equated to a $42 \%$ response rate. There were no significant correlations between transformational, transactional or passive/avoidant leadership behaviours and any of the research performance measures. The five transformational leadership behaviours (i.e., IA, IB, IM, IS, IC) were highly significant predictors of leadership outcomes; extra effort (all B>0.404, $\mathrm{SE}=0.093-0.146, \mathrm{p}<0.001$ ); effectiveness (IA, IM, IS, IC B>0.359, $\mathrm{SE}=0.093-$ 0.146, $\mathrm{p}<0.001 ; \mathrm{IB} \mathrm{B}=0.233, \mathrm{SE}=0.103, \mathrm{p}=0.026$ ); and satisfaction (IA, IM, IS, IC $\mathrm{B}>0.483$, $\mathrm{SE}=0.086-0.139, \mathrm{p}<0.001 ; \mathrm{IB} \mathrm{B}=0.296, \mathrm{SE}=0.101, \mathrm{p}=0.004)$. Similarly, contingent reward was a 
significant predictor of extra effort $(B=0.400, S E=0.123, p=0.002)$, effectiveness $(B=0.353$, $\mathrm{SE}=0.113, \mathrm{p}=0.002)$, and satisfaction $(\mathrm{B}=0.326, \mathrm{SE}=0.114, \mathrm{p}=0.005)$.

\section{Conclusions}

This study demonstrates that transformational leadership and contingent reward positively influence leadership efficiency in healthcare researchers. Although we did not show an association between leadership behaviours and research performance metrics, further studies utilising contextual performance measures at team and organizational levels are required.

\section{INTRODUCTION}

The healthcare sector has become a competitive market where Academic Healthcare Science Centres (AHSCs) compete with private organizations, in terms of quality and cost effectiveness, to deliver improved patient outcomes within the current fiscal constraints. Leadership is one of the critical factors to achieve organizational development and safety because it allows through decisive processes to create and execute vital objectives, modify thoughts and accomplish change.[1 2 2] Leaders benefit their healthcare organizations in many ways - including, importantly, in developing effective strategy and decision making and in creating a corporate culture focusing on high performance.[3]

In the academic healthcare setting, leadership is often perceived as an individual who commands authority and exercises supremacy, with exceptional aptitude. This interpretation of leadership is no longer sufficient, because of the multitude of challenges and problems that are faced by hospitals and academic healthcare centres. [4 5] Leadership can no longer be the effort of a single person, but will need to infiltrate all organizational levels and embrace those individuals who traditionally regarded themselves as leadership nonentities.[5] 
Effective leaders are pioneers in strategic decision-making, which generates high productivity that delivers "value to the client".[3] This transformational element of leadership is influential in developing mind-sets such as commitment, trust, cohesion and motivation, which increase individual and organizational performance. Organizations that encourage and cultivate transformational leadership are more constructive and successful, entice and retain higher performing employees, stimulate inventiveness and innovation, build effective teams, and are strategically placed to react well to fluctuations in the economic climate.[6]

The aims of this study were to: (i) determine associations between self-perceived leadership behaviours (transformational, transactional, passive/avoidant) and research performance variables in academic healthcare researchers; and (ii) evaluate whether self-perceived leadership behaviours in academic healthcare researchers are associated with enhanced leadership efficiency in terms of motivation, effectiveness and satisfaction.

\section{METHODS}

\section{Sample population}

The Faculty of Medicine Imperial College London, UK, was established in 1997, and is one of Europe's largest medical institutions.[7 8] It is organised into the Institute of Clinical Sciences, Kennedy Institute of Rheumatology, Department of Medicine, National Heart and Lung Institute, School of Public Health, and Department of Surgery and Cancer.[7 8] We used the database from the university intranet to create a list of all the Faculty of Medicine Professors at Imperial College that were in employment on the $31^{\text {st }}$ December 2009. For each of the professors included in the study, we extracted the first name, surname, gender, academic rank, physician status (i.e., whether the academic was a physician or non-physician scientist) and surgeon status (i.e. whether the academic was a surgeon or not). 


\section{Research performance variables}

We used SciVerse Scopus Author Identifier to generate the publication list authored by each professor.[7 9] If the search tool identified more than one publication list for a professor's name, then we combined the appropriate publication lists. For each professor, we examined the publication list and excluded any publications that were not attributable to the individual professor. For each professor, we extracted the total number of publications; total number of citations; and $\mathrm{h}$ index (A researcher has index $h$ if $h$ of his/her $N_{p}$ papers have at least $h$ citations each, and the other $\left(N_{p}-h\right)$ papers have no more than $h$ citations each) for the time period January $1^{\text {st }} 2007$ to December $31^{\text {st }} 2009$. We also calculated the total number of publications prior to January $1^{\text {st }} 2007$.

\section{Survey instrument}

In the published literature, the Multifactor Leadership Questionnaire (MLQ) is one of the most established methods to evaluate leadership behaviours.[10] Initially it consisted of 73 items, but the most recent version has been refined to 45 items that measure nine factors outlined in the FullRange Model of Leadership (Figure 1) (Table 1).[10] 
Table 1: Leadership styles and their components

\begin{tabular}{|c|c|c|}
\hline Leadership Styles & Components & Description \\
\hline \multirow{5}{*}{$\begin{array}{l}\text { Transformational } \\
\text { Leadership }\end{array}$} & Idealized influence attributes (IA) & $\begin{array}{l}\text { Earn respect of others by your actions, } \\
\text { followers keen to take on values and } \\
\text { attributes of their leaders }\end{array}$ \\
\hline & Idealized influence behaviours (IB) & $\begin{array}{l}\text { Follower behaviour takes example from } \\
\text { leaders own actions. Moral and ethical } \\
\text { effects of decisions are considered }\end{array}$ \\
\hline & Inspirational motivation (IM) & $\begin{array}{l}\text { Motivate followers to envisage appealing } \\
\text { prospects, leading them to eventually dream } \\
\text { by themselves }\end{array}$ \\
\hline & Intellectual stimulation (IS) & $\begin{array}{l}\text { Encourage creativity and originality by } \\
\text { probing ideas, restructuring difficulties and } \\
\text { handling issues in innovative ways }\end{array}$ \\
\hline & Individual consideration (IC) & $\begin{array}{l}\text { Individual counselling and mentorship, } \\
\text { leads to empowerment and development of } \\
\text { individual abilities }\end{array}$ \\
\hline \multirow{2}{*}{$\begin{array}{l}\text { Transactional } \\
\text { Leadership }\end{array}$} & Contingent reward (CR) & $\begin{array}{l}\text { Rewards and reprimands given are based } \\
\text { upon performance. Leads to personal and } \\
\text { collective accomplishment of anticipated } \\
\text { performance }\end{array}$ \\
\hline & Management-by-exception: active (MBEA) & $\begin{array}{l}\text { Careful observation of deviations from } \\
\text { benchmarks, errors or misdeeds, swiftly } \\
\text { followed by remedial action }\end{array}$ \\
\hline \multirow{2}{*}{$\begin{array}{l}\text { Passive/ avoidant } \\
\text { Leadership }\end{array}$} & Management-by-exception: passive (MBEP) & $\begin{array}{l}\text { Avoids action until significant problems } \\
\text { occur. Doesn't believe in mending things } \\
\text { until broken }\end{array}$ \\
\hline & Laissez-faire (LF) & $\begin{array}{l}\text { Abstains from important decision making, } \\
\text { defers answering imperative questions, does } \\
\text { not attend when required }\end{array}$ \\
\hline
\end{tabular}

We used the MLQ Self form, which is the self-rating part of the MLQ and which measures selfperceptions of leadership behaviours (Appendix).[10] Furthermore, the MLQ Self form measures self-perception of three leadership outcomes of interest, namely motivation, effectiveness and satisfaction (Table 2). 
Table 2: Description of leadership outcomes

\begin{tabular}{|l|l|}
\hline \multicolumn{1}{|c|}{ Outcomes } & \multicolumn{1}{c|}{ Descriptions } \\
\hline Extra Effort & $\begin{array}{l}\text { I am able to lead colleagues in accomplishing more than their anticipations, uplift } \\
\text { colleagues' hunger to achieve and enhance colleagues' eagerness to invest more } \\
\text { energy }\end{array}$ \\
\hline Effectiveness & $\begin{array}{l}\text { How effective I perceive myself as a leader. I am successful in accomplishing } \\
\text { colleagues' employment related goals, successful in achieving organizational } \\
\text { necessities and in directing a team that is prosperous }\end{array}$ \\
\hline Satisfaction & $\begin{array}{l}\text { Reflects how satisfied I am with my leadership outcomes. I employ systems of } \\
\text { leadership that are fulfilling and collaborate with colleagues in an agreeable manner }\end{array}$ \\
\hline
\end{tabular}

The survey instrument administered in this study was used with permission given by Mind Garden Incorporation located in Menlo Park, California, USA. The source document for this survey was: Multifactor Leadership Questionnaire Third Edition Manual and Sample Set by Bernard Bass and Bruce Avolio; Menlo Park, California: Mind Garden Incorporation, 2004.[10] The source document demonstrates robust evidence for validity, including factorial validation, and moderate to good reliability indices.[10]

\section{Statistical analysis}

We anonymised the data and obtained descriptive statistics to summarise the demographic, performance, and leadership variables. We tested data for normality using the Shapiro-Wilk test. Wilcoxon Mann-Whitney test was used to establish demographic differences in leadership behaviours. We used bivariate correlation (Spearman's Rank for non-normally distributed data) to determine the relationship between independent variables (demographic and leadership), and dependent variables (performance). Data that were non-normally distributed were $\log _{10}$ transformed before univariate regression analyses were performed between independent and dependent variables. All statistical analyses were performed on SPSS Statistics for Macintosh, Version 21.0. Armonk, NY: IBM Corporation, released 2012. 


\section{RESULTS}

A total number of 90 responses were received out of 215 surveyed professors, which equated to a $42 \%$ response rate. Out of the 90 respondents 65 were male $(72 \%)$ and 48 were physicians $(53 \%)$. Out of the 48 physicians, 14 were surgeons (29\%). Table 3 summarizes the descriptive statistics for the research performance variables.

Table 3: Means, standard deviations, and minimum and maximum values for research performance variables

\begin{tabular}{l|llll}
\multicolumn{1}{c|}{$\begin{array}{c}\text { Research performance } \\
\text { variables }\end{array}$} & Mean & $\begin{array}{c}\text { Standard } \\
\text { Deviation }\end{array}$ & Minimum & Maximum \\
\hline & & & & \\
Previous publications & 96.84 & 143.51 & 2.00 & 1013.00 \\
H index & 13.41 & 12.29 & 0.00 & 58.00 \\
Number of publications & 48.98 & 73.76 & 0.00 & 434.00 \\
Number of citations & 1714.00 & 2008.31 & 54.00 & 11534.00
\end{tabular}

\section{Leadership descriptive scores}

Figure S1 illustrates the distribution of survey scores for transformational, transactional, passive/avoidant and outcomes of leadership. The MLQ manual defines research-validated benchmark scores for an optimal leadership profile that supports the best leadership outcomes for individuals, teams and organizations. Figure 2 outlines these benchmark scores and illustrates the number of respondents that accomplished these scores. Over $50 \%$ of respondents showed optimal leadership profiles when considering research validated benchmark scores for transformational, transactional and passive/avoidant leadership characteristics. However, less than $40 \%$ of respondents showed favourable scores for all three leadership outcomes domains. Physicians had significantly higher scores than non-physicians for the leadership behaviours 'idealized attributes' and 'inspirational motivation' (mean \pm sd: $3.121 \pm 0.512$ vs. $2.873 \pm 0.571, \mathrm{p}=0.041$ and $3.390 \pm 0.519$ 
vs. $2.990 \pm 0.400, \mathrm{p}=0.002$ respectively). There were no statistically significant differences in leadership characteristics between gender or surgeon status.

\section{Correlational analysis}

Table 4 shows a 'heat map' of the bivariate correlations between research performance measures, leadership behaviours and leadership outcomes - where darker colours indicate higher absolute correlations. There were no significant correlations between transformational, transactional or passive/avoidant leadership behaviours and any of the research performance measures (i.e. number of publications, number of citations and $\mathrm{h}$ index). The five transformational leadership behaviours (i.e., IA, IB, IM, IS, IC) and contingent reward had a significant positive correlation with all three leadership outcomes (i.e., EE, EFF, SAT) (all rs $>0.31, \mathrm{p}<0.01$ ). Management-by-exception (active) had a significant positive correlation with effectiveness, but the enormity of the correlation was less than that of contingent reward ( $\mathrm{rs}=0.23, \mathrm{p}<0.032)$. The concept of a discrete passiveavoidant leadership model was reinforced by the fact that management-by-exception (passive) and laissez-faire behaviours had a significant negative correlation with effectiveness ( $\mathrm{rs}=-0.24, \mathrm{p}<$ $0.024 ; \mathrm{rs}=-0.26, \mathrm{p}<0.012$, respectively) 
Table 4: Bivariate correlations between measures of research performance, leadership behaviours and leadership outcomes (red $=$ negative correlation, green $=$ positive correlation)

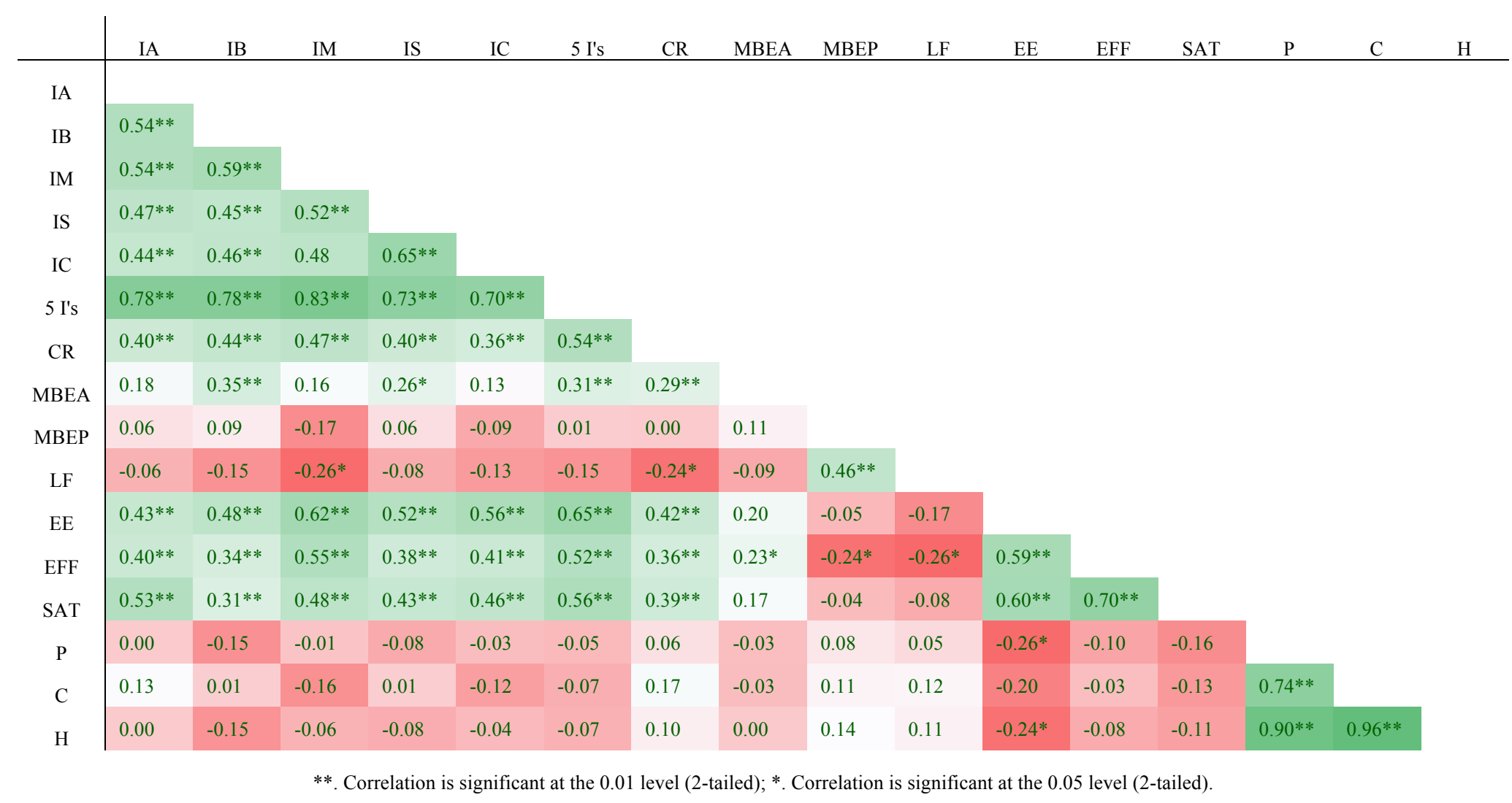

Idealized Attributes $=$ IA, Idealized Behaviours $=$ IB, Inspirational Motivation $=$ IM, Intellectual Stimulation $=$ IS, Individualized Consideration $=$ IC, Five I's of Transformational Leadership $=5$ I's, Contingent Reward $=$ CR, Management-by-Exception (Active) $=$ MBEA, Management-by-Exception $($ Passive $)=$ MBEP, Laissez-faire $=$ LF, Extra Effort $=$ EE Effectiveness $=$ EFF, Satisfaction $=$ SAT, Total number of publications $=\mathrm{P}$, Total number of citations $=\mathrm{C}, \mathrm{H}$ Index $=\mathrm{H}$ 


\section{Regression analysis}

Table S2 (Appendix) shows the results of the univariate regression analyses between all three research performance measures and demographic variables. The number of previous publications was a significant predictor of the number of publications $(B=0.471, S E=0.110, p<0.0001)$, number of citations $(\mathrm{B}=0.002, \mathrm{SE}=0.0003, \mathrm{p}<0.0001)$ and $\mathrm{h}$ index $(\mathrm{B}=0.265, \mathrm{SE}=0.080, \mathrm{p}<$ 0.002). The Cardio-Respiratory scientific field had a statistically significant positive influence on the number of publications $(B=0.443, S E=0.212, p=0.040)$ and $h$ index $(B=0.302, S E=0.153$, $\mathrm{p}=0.052$ ). The Surgery and Cancer scientific field had a statistically significant negative influence on the number of publications $(\mathrm{B}=-0.449, \mathrm{SE}=0.190, \mathrm{p}=0.020)$ and $\mathrm{h}$ index $(\mathrm{B}=-0.274, \mathrm{SE}=$ $0.137, \mathrm{p}=0.049)$.

Table S3 (Appendix) shows the results of the univariate regression analyses between all three research performance measures and transformational, transactional and passive/avoidant leadership behaviours. There were no statistically significant relationships between leadership behaviours and research performance.

Table S4 (Appendix) shows the results of the univariate regression analyses between all three leadership outcomes and demographic variables. There were no statistically significant relationships between demographic variables and leadership outcomes.

Table S5 (Appendix) shows the results of the univariate regression analyses between all three leadership outcomes and transformational, transactional and passive/avoidant leadership behaviours. The five transformational leadership behaviours were highly significant predictors of extra effort (all B > 0.404, $\mathrm{SE}=0.093-0.146, \mathrm{p}<0.001$ ), effectiveness (IA, IM, IS, IC B $>0.359$, $\mathrm{SE}=0.093-0.146, \mathrm{p}<0.001 ; \mathrm{IB} \mathrm{B}=0.233, \mathrm{SE}=0.103, \mathrm{p}=0.026)$, and satisfaction (IA, IM, IS, IC $\mathrm{B}>0.483, \mathrm{SE}=0.086-0.139, \mathrm{p}<0.001 ; \mathrm{IB} \mathrm{B}=0.296, \mathrm{SE}=0.101, \mathrm{p}=0.004)$. Similarly, contingent reward was a significant predictor of extra effort $(B=0.400$, SE $0.123, p=0.002)$, 
effectiveness $(\mathrm{B}=0.353, \mathrm{SE}=0.113, \mathrm{p}=0.002)$, and satisfaction $(\mathrm{B}=0.326, \mathrm{SE}=0.114, \mathrm{P}=$ 0.005), although the influence was less than that of transformational leadership behaviours.

\section{DISCUSSION}

The principal aim of this study was to gain a better comprehension of the associations between leadership behaviours and academic healthcare research performance. Many studies employing the MLQ have demonstrated that transformational leadership has a significant positive influence on individual and organizational success in areas as diverse as the banking, oil, military and government-run industrial sectors, though the measures of success are often leadership outcomes that are incorporated in the MLQ.[11 12] Fewer studies have used alternative objective performance measures, and in these studies the dependent variables are invariably connected to financial data.[13 14] This is the first study to our knowledge to link self-perceptions of leadership to objective research performance metrics. We did not find strong associations between transformational, transactional or passive/avoidant leadership and research performance.

We chose to examine leadership behaviours in Professorial grade because the title and position of professor in UK academic institutions personifies an individual who is an expert and academic leader in a particular subject discipline. It has long been regarded as a position denoting the peak of an academic career.[15] A professor is required to balance academic duty and freedom, and by way of intellectual leadership, they are required to be an academic citizen, knowledge producer, boundary transgressor and public intellectual.[16] Transformational leadership encompasses intellectual leadership, and hence we chose the MLQ to measure leadership behaviour in our cohort because it has become the benchmark measure of transformational leadership.[10 17]

Meta-analytic techniques have demonstrated that transformational leadership positively influences task and contextual performance at individual, team and organizational level, although there is a 
stronger association for the latter.[18] Task performance considers changing resources into commodities and services that are specific to the employment, the core technical skill. Contextual performance concerns aspects of an individual's performance that supports and augments an organization's social network and the psychological environment that serves as a catalyst for technical tasks.[19] The bibliometric measures of research performance that were used in this study have elements of both task and contextual performance constructs. On one hand, publishing is a crucial dimension of academia, and publications are one of the few tangible assets from an individual's research.[20] On the other hand, research requires a team effort and collaboration through social networks to be fruitful.[21] Unexpectedly, we did not find any strong links between transformational leadership and research performance. This may reflect the fact that we evaluated the relationship between leadership behaviour and leader performance, but this may not have entirely translated into performance outcomes of the individual follower or the professor's research team.[22] Moreover, transformational leadership, which focuses on team building and collaboration, may have an indirect association with research performance through stimulation of connectedness and social capital, which was not considered in this study.[23]

We did not demonstrate any gender differences in leadership behaviours, as well as leadership outcomes. Previous studies have shown that the differences in leadership behaviours and outcomes dissolve when leaders have similar specific role descriptions and work environments, such as government research organizations.[24] Women have succeeded in breaking through the maledominated structures of healthcare over time, but they continue to confront challenges in affirming their leadership and authority.[25] Notwithstanding this significant achievement, women still lag far behind men when it comes to senior ranks and board memberships, where they may exert a greater influence on organizational behaviour and strategy.[26 27] As an example, only a minority of women occupy chair and chief executive officer positions in healthcare institutions.[28] The expression "glass ceiling" describes women's absence of progression into prominent positions despite no evident obstacles.[29] Women who acquire the rank of full professor are given the 
opportunity for leadership in research, teaching, income generation and strategic organizational management. Moreover, female leaders are more transformational than their male counterparts, and have a higher commitment to contingent reward behaviours.[24] On the other hand, males are more prone to participate in the other facets of transactional leadership, as well as laissez-faire behaviours.[24] Consistently, women produce significantly better outcomes of leadership than men in all three variables evaluated in the MLQ.[24] In this study the preponderance of male professors in the cohort supports the notion of "glass ceiling", but perhaps gender equality in the institution has not come to fruition since the inception of specific policies from the Academic Opportunities Committee 16 years ago.[30]

Healthcare organizations and governing bodies that function to safeguard, promote and preserve the health and safety of the public empower physicians to have good values, morals and ethics.[31 32] The paradigm shift towards patient-centered care encourages physicians to concentrate medical attention on the individual patient's needs and concerns, rather than their own.[33] Over the last decade there has been substantial development in multidisciplinary team working throughout healthcare, where the focus has changed from individual physicians leading small groups to establishing bigger teams with broader responsibilities and less supremacy of the individual.[34] Within these teams, physicians have mutual trust and respect between team members, and different opinions are valued.[34] These contemporary changes in clinical medicine may explain why we found physician academics had significantly higher survey scores than their non-physicians equivalents for the transformational leadership behaviour 'idealized attributes'. Likewise, physician academics also had significantly higher survey scores for the transformational leadership behaviour 'inspirational motivation'. Differences in motivating factors between physician and non-physician academics may account for the disparity between self-perception of inspirational motivation.[35] The foremost motivating factor for physician academics is the impact they have on global health and this can magnetize others who share similar aspirations.[35] The contributions that nonphysician academics make to the process of translational research are less frequently 
considered.[35] They often face numerous scientific, institutional, cultural and policy barriers, which limit the chances to partake in translational science.[35] Empowering them to contribute to the understanding and development of innovation in human healthcare, as well as promoting collaborations with physicians and researchers, can be a source of inspirational motivation. [35 36]

Similarly to previous research, this study demonstrated high inter-correlation between transformational leadership behaviours and contingent reward implying that although discrete in actuality, they are associated with the same all-encompassing theoretical leadership concept.[11 37] Based on similar inter-correlations, several studies have also proposed a two-factor active (transformational and transactional) and passive (passive/avoidant) leadership model.[38]

Previous studies have shown that transformational leadership and contingent reward behaviour, although part of the transactional leadership domain, are positively associated with the three outcome variables of effectiveness, satisfaction, and extra effort.[37 39] Similarly, our findings suggest that for leadership to be effective, leaders should adopt and utilize both transformational and transactional contingent reward leadership behaviours. These leadership behaviours embrace the principles of effective leadership that include [40]: (i) building a common vision, mission and set of goals to help followers concentrate on their commitments and perform to their greatest ability; (ii) establishing a non-threatening communication network that encourages honest feedback and self-disclosure; (iii) creating infrastructure for knowledge transfer; (iv) developing trust, admiration and peer-based education; (v) being all-encompassing, tolerant, and emotionally intelligent; (vi) exhibiting ingenuity, innovativeness and the eagerness to learn; (vii) nurturing an environment that promotes unsurpassed performance.

A conceptual problem with leadership is that it is defined either through its effects or in operational terms by specifying its component parts.[41] Consequently, when surveys such as the MLQ measure transformational leadership there is conflation between cause and effect.[42] Additionally, 
leadership behaviours are often related to personality traits, for example transformational leadership is associated with extraversion.[43] Subsequently, individuals may find it difficult to think negatively or be overconfident when reflecting on their leadership skills.[44] In this study we found that the perception of leadership behaviours in the majority of respondents was better than the normative sample. However, the respondents' self-perception of their leadership outcomes was surprisingly lower. It is possible that respondents found it easier to rate themselves higher on leadership behaviours, because they were harder to objectively quantify than leadership outcomes. Another consistent explanation may be that the overconfidence effect was stronger for leadership behaviours, because they had closer association with personality traits than leadership outcomes.

There are several limitations to this study. We used the MLQ Self form that evaluates selfperception of leadership, and consequently there is potential for social desirability bias, where survey respondents exaggerate favourable or understate undesirable behaviour. The response rate to the survey was low, and the respondents were from a single institution and specific scientific field, so that the results of this study may not be generalisable to other settings. This was a crosssectional study, so we cannot determine cause and effect. We have only measured an individuals' research performance, so we could not determine the effect of leadership on research teams or the organization. Self-citations, field dependency and multi-authorship may disadvantage bibliometric performance measures.[45]

Future work should evaluate transformational leadership using 360-degree leadership assessment (MLQ 360) to diminish the bias of self-perception. Longitudinal studies may further elucidate longer-term positive effects of leadership - for example, does more effective leadership stimulate scientific collaborations, which then drive improved research performance? Multicentre studies across different specialities may uncover the genuine extent of transformational leadership on research performance. It is also imperative to include measures of team and organizational 
performance, alongside individual-based metrics, to investigate the full breadth of potential leadership effects.

\section{CONCLUSIONS}

This study shows that transformational leadership and contingent reward positively influence leadership efficiency in academic healthcare researchers, although we did not find positive associations between transformational leadership and research performance. The differences in transformational leadership behaviours between physician and non-physician academics may reflect the gap between basic research and translational medicine. To bridge the gap, leaders will need to build connectedness and social capital to facilitate information flow, knowledge transfer and communication across organizational barriers. Finally, as leadership is based on optimising positive relationships, the use of further contextual performance measures at team and organizational level in future research may provide further illustrations of the effect of leadership on research performance.

\section{REFERENCES}

1. Keroack MA, Youngberg BJ, Cerese JL, et al. Organizational factors associated with high performance in quality and safety in academic medical centers. Acad Med 2007;82(12):1178-86 doi: 10.1097/ACM.0b013e318159e1ff[published Online First: Epub Date]|.

2. Reinertsen JL, Bisognano M, Pugh MD. Seven Leadership Leverage Points for Organisation-Level Improvement in Health Care. 2nd ed. Cambridge, Massachusetts: Institute for Healthcare Improvement, 2008.

3. Buchanan DA, Addicott R, Fitzgerald L, et al. Nobody in charge: Distributed change agency in healthcareHuman Relations,60(7):1065-90. Human Relations;60(7):1065-90

4. Patel VM, Warren $O$, Humphris $P$, et al. What does leadership in surgery entail? ANZ J Surg 2010;80(12):876-83 doi: 10.1111/j.1445-2197.2010.05530.x[published Online First: Epub Date]|.

5. Souba WW. The new leader: new demands in a changing, turbulent environment. J Am Coll Surg 2003;197(1):79-87 doi: S1072-7515(03)00335-1 [pii]

10.1016/S1072-7515(03)00335-1[published Online First: Epub Date]|.

6. Avolio BJ. Full Range Leadership Development. 2nd ed. University of Washington, USA: SAGE Publications, 2011.

7. Patel VM, Ashrafian $\mathrm{H}$, Bornmann L, et al. Enhancing the $\mathrm{h}$ index for the objective assessment of healthcare researcher performance and impact. Journal of the Royal Society of Medicine 2013;106(1):19-29

8. Imperial College London: http://www1.imperial.ac.uk/medicine/about/. 2011

9. Elsevier. Scopus Website: http://www.scopus.com. 2004 
10. Bass BM, Avolio BJ. Multifactor Leadership Questionnaire Third Edition Manual and Sample Menlo Park, California: Mind Garden Incorporation, 2004.

11. Lowe KB, Kroeck KG, Sivasubramaniam N. Effectiveness correlates of transformational and transactional leadership: A meta-analytic review of the mlq literature. The Leadership Quarterly 1996;7(3):385425

12. Hoffman E. Psychological testing at work: McGraw-Hill, 2002.

13. Flanigan RL, Stewardson G, Dew J, et al. Effects of Leadership on Financial Performance at the Local Level of an Industrial Distributor. The Journal of Technology, Management, and Applied Engineering 2013;29(4)

14. Geyer ALJ, Steyrer JM. Transformational Leadership and Objective Performance in Banks. Journal of Applied Psychology 1998;47:397-420

15. Tight M. What does it mean to be a professor? Higher Education Review 2002;34:15-31

16. Macfarlane B. Intellectual leadership in higher education: Renewing the role of the university professor. New York: Routledge, 2012.

17. Burns JM. Leadership. New York: Harper \& Row, 1978.

18. Wang G, Oh I, Courtright SH, et al. Transformational Leadership and Performance Across Criteria and Levels: A Meta-Analytic Review of 25 Years of Research. 2011;36(2):223-70

19. Motowildo SJ, Borman WC, Schmidt N. A Theory of Individual Differences in Task and Contextual Performance. Human Performance 1997;10:71-83

20. Shapiro DW, Wenger NS, Shapiro MF. The contributions of authors to multiauthored biomedical research papers. JAMA 1994;271(6):438-42

21. Adams J. Collaborations: The rise of research networks. Nature 2012;490(7420):335-6 doi: 10.1038/490335a[published Online First: Epub Date]|.

22. Sparrowe RT, Liden RC, Wayne SJ, et al. Social Networks and the Performance of Individuals and Groups. The Academy of Management Journal 2001;44(2):316-25

23. Alves JC. A multilevel analysis of the association among individual capabilities, team leadership behaviors, and performance in China. Doctoral Dissertations Available from Proquest. Paper AAI3315480. http://scholarworks.umass.edu/dissertations/AAl3315480 2008

24. Eagly AH, Johannesen-Schmidt MC, van Engen ML. Transformational, transactional, and laissez-faire leadership styles: a meta-analysis comparing women and men. Psychological bulletin 2003;129(4):569-91

25. Hoss MAK, Bobrowski P, McDonagh KJ, et al. How gender disparities drive imbalances in health care leadership. Journal of Healthcare Leadership 2011;3:59-68

26. Burgess Z, Tharenou, P. Women board directors: Characteristics of the few. Journal of Business Ethics 2002;37:39-49

27. Oakley JG. Gender-based barriers to senior management positions: Understanding the scarcity of female CEOs. Journal of Business Ethics 2000;27:321-34

28. Lantz PM. Gender and leadership in healthcare administration: 21st century progress and challenges. Journal of healthcare management / American College of Healthcare Executives 2008;53(5):291301; discussion 02-3

29. Carnes M, Morrissey C, Geller SE. Women's health and women's leadership in academic medicine: hitting the same glass ceiling? Journal of women's health 2008;17(9):1453-62 doi: 10.1089/jwh.2007.0688[published Online First: Epub Date]|.

30. AOC. Equality and Diversity: accessed from http://www3.imperial.ac.uk/equality/women. Secondary Equality and Diversity: accessed from http://www3.imperial.ac.uk/equality/women 1998.

31. Good medical practice. Secondary Good medical practice 2014. http://www.gmcuk.org/Good_medical_practice_English_0414.pdf_51527435.pdf.

32. Good medical practice: a code of conduct for doctors in Australia. Secondary Good medical practice: a code of conduct for doctors in Australia 2014. http://www.medicalboard.gov.au/Codes-GuidelinesPolicies/Code-of-conduct.aspx.

33. Bardes CL. Defining "patient-centered medicine". The New England journal of medicine 2012;366(9):782-3 doi: 10.1056/NEJMp1200070[published Online First: Epub Date]|.

34. Carter S, Garside P, Black A. Multidisciplinary team working, clinical networks, and chambers; opportunities to work differently in the NHS. Qual Saf Health Care 2003;12 Suppl 1:i25-8 
35. Hobin JA, Deschamps AM, Bockman R, et al. Engaging basic scientists in translational research: identifying opportunities, overcoming obstacles. Journal of translational medicine 2012;10:72 doi: 10.1186/1479-5876-10-72[published Online First: Epub Date]|.

36. Souba WW. New ways of understanding and accomplishing leadership in academic medicine. J Surg Res 2004;117(2):177-86 doi: 10.1016/j.jss.2004.01.020[published Online First: Epub Date]|.

37. Horwitz IB, Horwitz SK, Daram P, et al. Transformational, transactional, and passive-avoidant leadership characteristics of a surgical resident cohort: analysis using the multifactor leadership questionnaire and implications for improving surgical education curriculums. J Surg Res 2008;148(1):49-59 doi: S0022-4804(08)00191-1 [pii]

10.1016/j.jss.2008.03.007[published Online First: Epub Date]|.

38. Bycio P, Hackett RD, Allen JS. Further assessments of Bass's (1985) conceptualization of transactional and transformational leadership. Journal of Applied Psychology 1995;80(4):468-78

39. Snodgrass J, Shachar M. Faculty perceptions of occupational therapy program directors' leadership styles and outcomes of leadership. Journal of allied health 2008;37(4):225-35

40. Cooper J, Nirenberg J. Leadership effectiveness. In: Goethals G, Sorenson G, Burns J, eds. Encyclopedia of leadership. Thousand Oaks, California: SAGE, 2004:845-54.

41. Van Knippenberg D, Sitkin SB. A critical assessment of charismatic-transformational leadership research: Back to the drawing board? The Academy of Management Annals 2013;7:1-60

42. Arnulf JK, Larsen KR, Martinsen OL, et al. Predicting survey responses: how and why semantics shape survey statistics on organizational behaviour. PloS one 2014;9(9):e106361 doi: 10.1371/journal.pone.0106361[published Online First: Epub Date]|.

43. Bono JE, Judge TA. Personality and transformational and transactional leadership: a meta-analysis. The Journal of applied psychology 2004;89(5):901-10 doi: 10.1037/0021-9010.89.5.901[published Online First: Epub Date]|.

44. Davis DA, Mazmanian PE, Fordis M, et al. Accuracy of physician self-assessment compared with observed measures of competence: a systematic review. JAMA 2006;296(9):1094-102 doi: 10.1001/jama.296.9.1094[published Online First: Epub Date]|.

45. Patel VM, Ashrafian $\mathrm{H}$, Almoudaris $\mathrm{A}$, et al. Measuring academic performance for healthcare researchers with the $\mathrm{H}$ index: which search tool should be used? Medical principles and practice : international journal of the Kuwait University, Health Science Centre 2013;22(2):178-83 doi: 10.1159/000341756[published Online First: Epub Date]|. 
Figure 1: The Full-Range Model of Leadership.[10]

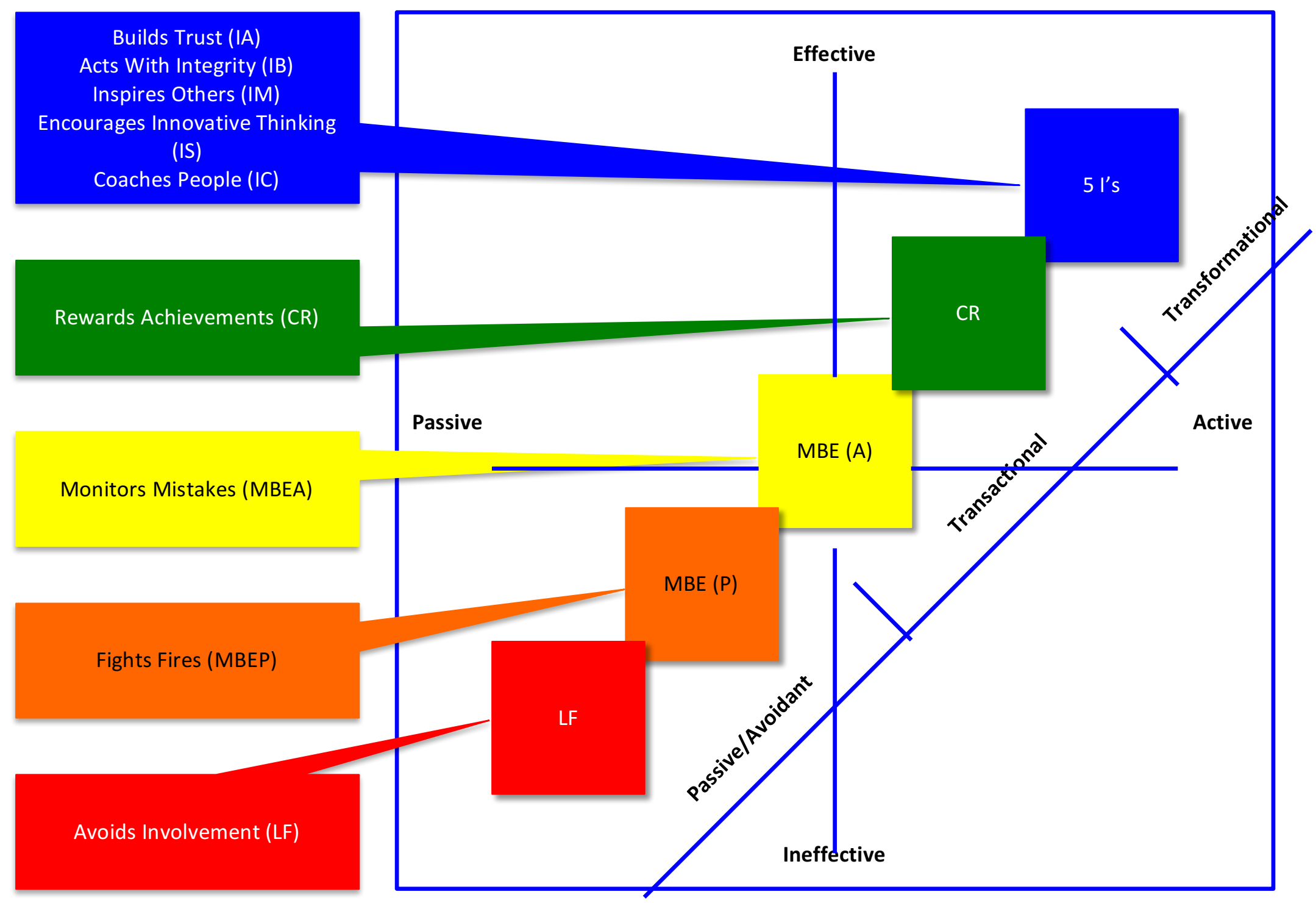


Figure 2: Bar chart showing percentage of respondents who scored the research validated benchmark (benchmark score in brackets) for each leadership characteristic.

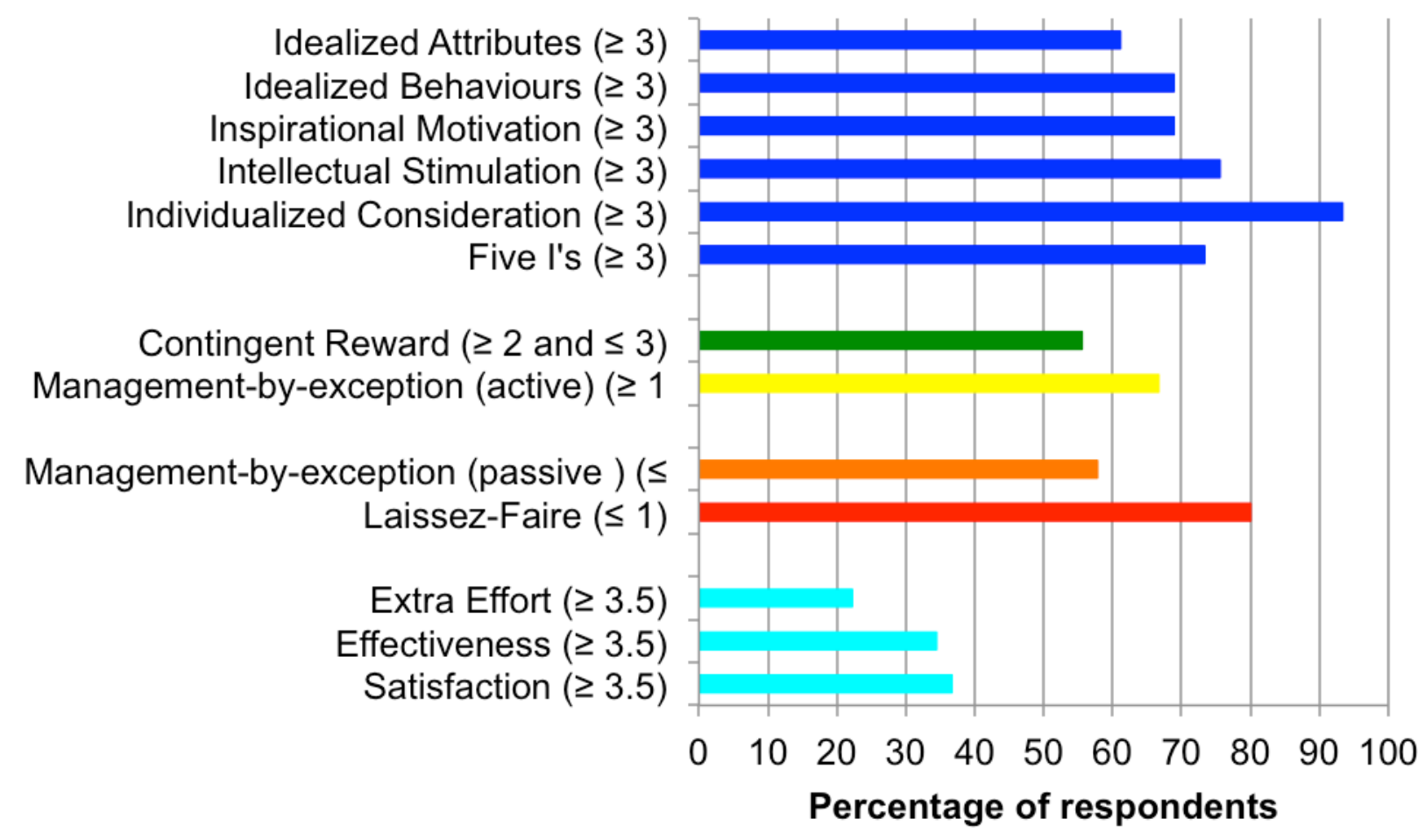




\section{MAIN MESSAGES}

- Transformational leadership and contingent reward positively influenced leadership efficiency in healthcare researchers.

- In healthcare researchers, self-perception of leadership behaviour was overinflated in comparison to self-perception of leadership outcome.

- There were no significant relationships between transformational, transactional or passive/avoidant leadership and healthcare research performance.

\section{CURRENT RESEARCH QUESTIONS}

- Are there confounding variables, such as teamwork, network and management skills, that influence leadership behaviours and healthcare research performance?

- What impact does leadership have on team and organizational research performance?

- What influence does leadership have on clinical performance? 


\section{APPENDIX}

\section{Extracting leadership variables}

Table S1 shows a sample of five descriptive items that were used to assess self-perception of leadership behaviours and leadership outcomes. Each participant was asked to judge how frequently each item fits him or her using the following Likert rating scale:

$4=$ frequently if not always

3 = fairly often

$2=$ sometimes

$1=$ once in a while

$0=$ not at all

4. I focus attention on irregularities, mistakes, exceptions, and deviations from standards

18. I go beyond self-interest for the good of the group

23. I consider the moral and ethical consequences of decisions

29. I consider an individual as having different needs, abilities, and aspirations from others

43. I am effective in meeting organizational requirements

Table S1: A sample of five descriptive items from Multifactor Leadership Questionnaire.

Copyright 1995, 2000, 2004 by Bernard Bass and Bruce Avolio. All rights reserved. Published by

Mind Garden, Inc., www.mindgarden.com.

A range of two to four items corresponded to each leadership behaviour or leadership outcome. For each professor and for each leadership behaviour or leadership outcome the mean score was calculated from the corresponding items. 


\begin{tabular}{|c|c|c|c|c|c|c|c|c|c|c|c|c|}
\hline & \multicolumn{4}{|c|}{ Number of publications } & \multicolumn{4}{|c|}{ Number of citations } & \multicolumn{4}{|c|}{$h$ index } \\
\hline & B & SE & $C I-L$ & $\mathbf{C I}-\mathbf{U}$ & B & SE & CI - L & CI - U & B & SE & CI - L & CI - U \\
\hline \multicolumn{13}{|l|}{ Individual variables } \\
\hline Previous publications & $.471 * *$ & .110 & .252 & .690 & $.002 * *$ & .000 & .001 & .002 & $.265 * *$ & .080 & .105 & .425 \\
\hline Male & .257 & .144 & -.031 & .544 & .153 & .123 & -.093 & .398 & .054 & .094 & -.134 & .243 \\
\hline Physician & $.364 * *$ & .113 & .137 & .590 & $.211^{*}$ & .107 & -.003 & .425 & $.154^{*}$ & .074 & .007 & .301 \\
\hline Surgeon & -.063 & .250 & -.559 & .433 & -.010 & .156 & -.321 & .302 & -.065 & .179 & -.421 & .291 \\
\hline \multicolumn{13}{|l|}{$\underline{\text { Scientific field }}$} \\
\hline Clinical Sciences & -.728 & .498 & -1.718 & .262 & -.008 & .436 & -.880 & .863 & -.495 & .358 & -1.207 & .216 \\
\hline Medicine & .126 & .187 & -.246 & .498 & -.104 & .112 & -.327 & .120 & .034 & .135 & -.234 & .302 \\
\hline Cardio Respiratory & $.443 *$ & .212 & .021 & .865 & .070 & .123 & -.175 & .316 & $.302 *$ & .153 & -.002 & .606 \\
\hline Public Health & .223 & .362 & -.497 & .942 & .131 & .201 & -.271 & .532 & .235 & .259 & -.280 & .751 \\
\hline Surgery and Cancer & $-.449 *$ & .190 & -.825 & -.072 & .006 & .128 & -.251 & .262 & $-.274 *$ & .137 & -.547 & -.001 \\
\hline
\end{tabular}

$\Psi . \%$ Non-alphabetical author sequence publications. $* \mathrm{p} \leq 0.05, * * \mathrm{p} \leq 0.01$

Table S2: Univariate regression analyses between measures of research performance (dependent variable) and demographic variables. 


\begin{tabular}{|c|c|c|c|c|c|c|c|c|c|c|c|c|}
\hline & \multicolumn{4}{|c|}{ Number of publications } & \multicolumn{4}{|c|}{ Number of citations } & \multicolumn{4}{|c|}{$h$ index } \\
\hline & B & SE & CI - L & CI - U & B & SE & CI - L & CI - U & B & SE & CI - L & CI - U \\
\hline \multicolumn{13}{|c|}{$\underline{\text { Transformational }}$} \\
\hline IA & -.508 & 1.079 & -2.652 & 1.637 & .400 & .619 & -.838 & 1.639 & -.247 & .776 & -1.788 & 1.295 \\
\hline IM & .318 & 1.173 & -2.013 & 2.648 & -.891 & .790 & -2.471 & .689 & .189 & .842 & -1.485 & 1.864 \\
\hline IS & -1.211 & 1.420 & -4.033 & 1.611 & .226 & .920 & -1.615 & 2.067 & -.786 & 1.021 & -2.815 & 1.242 \\
\hline IC & -.231 & 1.739 & -3.686 & 3.225 & -.805 & 1.068 & -2.942 & 1.331 & -.144 & 1.249 & -2.626 & 2.338 \\
\hline \multicolumn{13}{|c|}{$\underline{\text { Transactional }}$} \\
\hline $\mathrm{CR}$ & 1.065 & 1.274 & -1.466 & 3.597 & 1.620 & .919 & -.218 & 3.458 & 1.059 & .912 & -.753 & 2.870 \\
\hline MBEA & .143 & .402 & -.656 & .942 & -.283 & .290 & -.863 & .297 & .124 & .289 & -.450 & .698 \\
\hline \multicolumn{13}{|c|}{ Passive/Avoidant } \\
\hline MBEP & .353 & .390 & -.422 & 1.129 & .279 & .231 & -.184 & .741 & .311 & .280 & -.246 & .867 \\
\hline LF & .443 & .398 & -.349 & 1.236 & .301 & .265 & -.232 & .833 & .274 & .288 & -.299 & .848 \\
\hline
\end{tabular}

Idealized Attributes $=$ IA, Idealized Behaviours $=$ IB, Inspirational Motivation $=$ IM, Intellectual Stimulation $=$ IS, Individualized Consideration $=$ IC, Five I's of Transformational Leadership $=5$ I's, Contingent Reward $=$ CR, Management-by-Exception (Active) $=$ MBEA, Management-by-Exception $($ Passive $)=$ MBEP, Laissez-faire $=$ LF. $* \mathrm{p} \leq 0.05, * * \mathrm{p} \leq 0.01$

Table S3: Univariate regression analyses between measures of research performance (dependent variable) and leadership behaviours. 


\begin{tabular}{|c|c|c|c|c|c|c|c|c|c|c|c|c|}
\hline & \multicolumn{4}{|c|}{ Extra effort } & \multicolumn{4}{|c|}{ Effectiveness } & \multicolumn{4}{|c|}{ Satisfaction } \\
\hline & B & SE & CI - L & CI - U & B & SE & CI - L & $\mathrm{CI}-\mathrm{U}$ & B & SE & CI - L & CI - U \\
\hline \multicolumn{13}{|l|}{$\underline{\text { Individual variables }}$} \\
\hline Previous publications & -.012 & .021 & -.055 & .030 & -.003 & .019 & -.041 & .035 & -.024 & .019 & -.062 & .014 \\
\hline Male & .016 & .024 & -.032 & .064 & -.024 & .020 & -.064 & .016 & -.020 & .021 & -.063 & .022 \\
\hline Physician & -.006 & .022 & -.049 & .037 & .008 & .018 & -.028 & .044 & -.001 & .019 & -.040 & .037 \\
\hline Surgeon & .046 & .025 & -.004 & .095 & -.019 & .023 & -.065 & .027 & -.020 & .023 & -.066 & .026 \\
\hline \multicolumn{13}{|l|}{$\underline{\text { Scientific field }}$} \\
\hline Clinical Sciences & .014 & .051 & -.088 & .116 & .017 & .047 & -.076 & .111 & .022 & .047 & -.071 & .116 \\
\hline Medicine & -.009 & .019 & -.047 & .029 & .012 & .017 & -.023 & .047 & .023 & .017 & -.012 & .058 \\
\hline Cardio Respiratory & .001 & .022 & -.043 & .045 & -.019 & .020 & -.059 & .021 & -.012 & .020 & -.052 & .028 \\
\hline Public Health & -.065 & .036 & -.137 & .008 & .010 & .034 & -.057 & .077 & -.045 & .033 & -.112 & .021 \\
\hline Surgery and Cancer & .026 & .020 & -.014 & .065 & -.003 & .018 & -.039 & .033 & -.005 & .018 & -.041 & .031 \\
\hline
\end{tabular}

$\Psi . \%$ Non-alphabetical author sequence publications. $* \mathrm{p} \leq 0.05, * * \mathrm{p} \leq 0.01$

Table S4: Univariate regression analyses between measures of leadership outcomes (dependent variable) and demographic variables. 


\begin{tabular}{|c|c|c|c|c|c|c|c|c|c|c|c|c|}
\hline & \multicolumn{4}{|c|}{ Extra effort } & \multicolumn{4}{|c|}{ Effectiveness } & \multicolumn{4}{|c|}{ Satisfaction } \\
\hline & B & SE & CI - L & $\mathrm{CI}-\mathrm{U}$ & B & SE & CI - L & CI - U & B & SE & CI - L & CI - U \\
\hline \multicolumn{13}{|c|}{$\underline{\text { Transformational }}$} \\
\hline IA & $.404 * *$ & .101 & .203 & .606 & $.359 * *$ & .093 & .173 & .544 & $.487 * *$ & .086 & .317 & .658 \\
\hline IM & $.708^{* *}$ & .093 & .524 & .892 & $.571 * *$ & .091 & .390 & .752 & $.483 * *$ & .096 & .291 & .674 \\
\hline IS & $.689 * *$ & .125 & .440 & .938 & $.538 * *$ & .120 & .299 & .777 & $.589 * *$ & .119 & .352 & .826 \\
\hline IC & $.944 * *$ & .146 & .654 & 1.234 & $.665 * *$ & .146 & .375 & .956 & $.784 * *$ & .139 & .509 & 1.059 \\
\hline \multicolumn{13}{|c|}{ Transactional } \\
\hline $\mathrm{CR}$ & $.400 * *$ & .123 & .155 & .645 & $.353 * *$ & .113 & .128 & .578 & $.326 * *$ & .114 & .100 & .552 \\
\hline MBEA & .066 & .040 & -.014 & .146 & .058 & .037 & -.016 & .131 & .035 & .037 & -.039 & .109 \\
\hline \multicolumn{13}{|c|}{$\underline{\text { Passive/Avoidant }}$} \\
\hline MBEP & -.007 & .040 & -.087 & .073 & -.069 & .037 & -.142 & .003 & -.003 & .037 & -.077 & .071 \\
\hline LF & -.037 & .040 & -.117 & .042 & -.067 & .038 & -.143 & .008 & -.040 & .038 & -.115 & .034 \\
\hline
\end{tabular}

Idealized Attributes $=$ IA, Idealized Behaviours $=$ IB, Inspirational Motivation $=$ IM, Intellectual Stimulation $=$ IS, Individualized Consideration $=$ IC, Five I's of

Transformational Leadership = 5 I's, Contingent Reward $=$ CR, Management-by-Exception $($ Active $)=$ MBEA, Management-by-Exception $($ Passive $)=$ MBEP, Laissez-faire $=$

LF. $* \mathrm{p} \leq 0.05, * * \mathrm{p} \leq 0.01$

Table S5: Univariate regression analyses between measures of leadership outcomes (dependent variable) and leadership behaviours 
Figure S1: Box plots showing distribution of survey scores for transformational leadership, transactional leadership, passive/avoidant and outcomes of leadership.
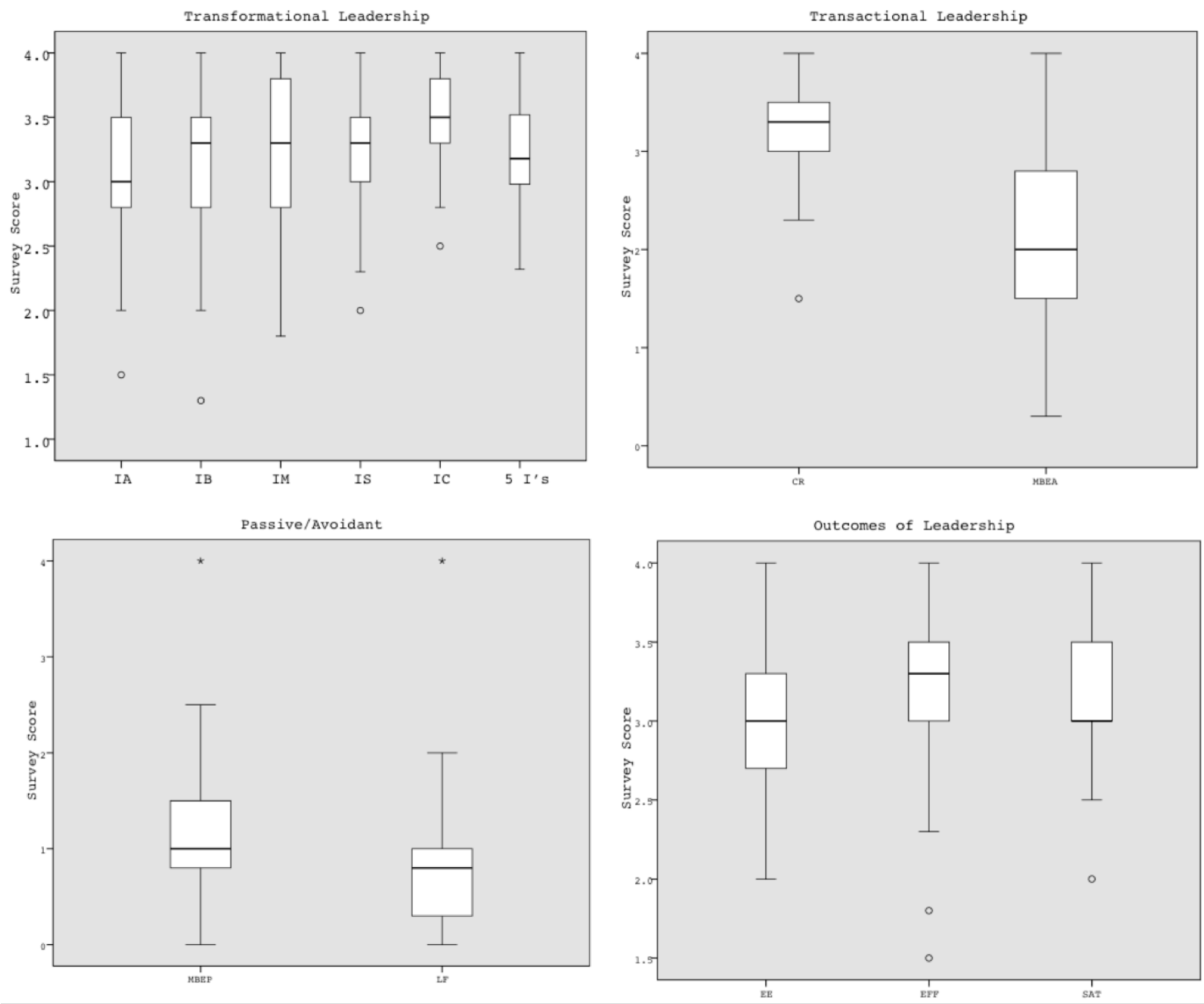